Research Article

\title{
Analysis of the Vibration and Chatter Stability of a Tapered Composite Boring Bar
}

\author{
Chunjin Zhang $\mathbb{D}^{1},{ }^{1}$ Yongsheng Ren ${ }^{(D)},{ }^{1}$ Shujuan Ji, ${ }^{2}$ and Jinfeng Zhang ${ }^{1}$ \\ ${ }^{1}$ College of Mechanical and Electronic Engineering, Shandong University of Science and Technology, Qingdao 266590, China \\ ${ }^{2}$ College of Computer Science and Engineering, Shandong University of Science and Technology, Qingdao 266590, China
}

Correspondence should be addressed to Chunjin Zhang; zhangchjin@163.com

Received 31 January 2020; Revised 8 May 2020; Accepted 25 May 2020; Published 27 June 2020

Academic Editor: Fiorenzo A. Fazzolari

Copyright ( $(2020$ Chunjin Zhang et al. This is an open access article distributed under the Creative Commons Attribution License, which permits unrestricted use, distribution, and reproduction in any medium, provided the original work is properly cited.

As metal boring bars have low dynamic stiffness, chatter is easily induced during the boring process. Therefore, improvement of the chatter stability is an open problem that requires further study. Though researchers proved that the composite materials suitable for making tapered boring bars can further improve the dynamic stiffness to meet the need of high-speed boring, existing research studies did not study the dynamic characteristics of the tapered composite boring bar comprehensively. In particular, no research has been done about the natural frequency and chatter stability of the composite boring bar under various taper ratios. Therefore, in this paper, a model of a tapered composite boring bar is established based on the Adomian modified decomposition method (AMDM). Second, this paper verifies the effectiveness of the AMDM by using the ANSYS software. Moreover, this paper studies the natural frequency of the boring bar model under various situations. Third, we verify the convergence of chatter stability of the boring bar model. Finally, the chatter stability of the tapered composite boring bar is analyzed comprehensively. The results show that the natural frequency and the chatter stability of the tapered model can be improved by choosing appropriate taper ratio, ply angle, stacking sequences, $L / D$ ratio, $T / D$ ratio, and the carbon composite. The results are helpful for the design of high-quality tapered composite boring bars matching the need of high speed cutting. In particular, these results can provide guidelines for adjusting the cutting speed in CNC boring and can further improve the surface finish of the machined workpieces.

\section{Introduction}

Boring bars are tools for boring cylinders that are often used in machine manufacturing. When boring deep holes, the boring bar must be slender, because bore holes often are deep and narrow. In the past, most boring bars were made of metal materials. However, it was found that this kind of boring bar can only bore holes with an $L / D$ ratio that is less than five. Moreover, metal boring bars possess low dynamic stiffness, and thus, chatter easily occurs during boring. Chatter worsens the surface finish of the machined workpieces, causing them to fail to meet accuracy requirements and affecting the quality of the parts.

To overcome the chatter problem of metal materials, many scholars [1-13] have conducted studies and found that chatter is often generated by three factors, i.e., ripple regeneration, mode coupling, and friction. In the study of ripple regeneration (which is caused by surface ripples), Luo et al. [14] adopted a hybrid digital method to solve the problem of surface ripple regeneration. Altintas and Weck [15] studied the stability of regenerative chatter during metal cutting. Litak [16] analyzed the vibrations generated by vertical cutting and used a one-degree-of-freedom model to simulate the complex system of regenerative cutting. In the field of mode coupling, Tulasiramarao et al. [17] analyzed the stability of the coupling between the cutting tool and the machined workpieces. KalmárNagy and Moon [18] studied the mode coupling of the vibrations. Gasparetto [19] studied the system theory of mode coupling from two perspectives. In the study of friction regeneration, $\mathrm{Wu}$ et al. $[20,21]$ created a dynamic friction mechanical model to predict the cutting force and validated it. These studies were of great 
significance to understand the occurrence of chatter. However, they did not fundamentally solve the problem of chatter caused by high-speed cutting.

Using composite materials with a high dynamic stiffness to fabricate boring bars is an effective way to suppress chatter during high-speed and deep-hole cutting. Researchers have sought suitable composite materials to fabricate boring bars. For example, Nagano et al. [22] designed a composite boring bar with an iron core and proved that when this boring bar was applied, chatter did not occur when the $L / D$ ratio was less than 7 . Furthermore, Lee et al. [23] designed a carbon fiber composite boring bar with a damping layer and proved that the $L / D$ ratio could reach 10.7 without chatter. Considering shear deformation and rotational inertia, Zhang et al. [24] analyzed the dynamic characteristics of composite boring bar. The analysis results show that the shear deformation and rotational inertia affect the vibration mode shapes of the composite boring bar and reduce its natural frequency and chatter stability. Although these efforts have advanced the field of research, it is unclear whether there is a better method to increase the dynamic stiffness.

Tapered boring bars exhibit higher dynamic stiffness than those of the uniform boring bars. And many scholars have studied this type of beam model. For example, Goel [25] investigated the transverse vibrations of linearly tapered beams that were elastically restrained against rotation at either end. Laura and Gutierrez [26] studied the vibrations of a cantilevered beam of varying cross section using an approximate solution based on the Rayleigh-Schmidt approach. Grossi et al. [27] used a set of orthogonal polynomials in the Rayleigh-Ritz method to study the vibrations of tapered beams. Ho and Chen [28] used a differential transform to solve the free and forced vibration problems of nonuniform beams. Abrate [29] used the Rayleigh-Ritz method to study the free vibrations of nonuniform beams. De Rosa and Auciello [30] examined the dynamic characteristics of beams with linearly varying cross sections. Ren et al. [31] analyzed the influence of the taper ratio on the natural frequencies characteristics of the composite boring bar.

In all the above studies, researchers did not study the dynamic characteristics of the tapered composite boring bar comprehensively. In particular, the natural frequency and chatter stability of the composite boring bar under various taper ratios have not been examined. However, it is proved that the study of this problem can provide guidelines for adjusting the cutting speed in CNC boring, reduce the chatter, protect the boring cutter, achieve efficient cutting, and finally improve the surface finish of the machined workpieces.

Therefore, this paper first presents a model for tapered composite boring bar based on the Adomian modified decomposition method (AMDM). Second, this paper verifies the effectiveness of the AMDM by using the ANSYS software. Moreover, this paper studies the natural frequency of the boring bar model under different ply angles, length to diameter $(L / D)$ ratios, thickness to diameter $(T / D)$ ratios, and three types of composite materials in detail. Third, we verify the convergence of chatter stability of the boring bar model. Finally, the chatter stability of the tapered composite boring bar is analyzed under different taper ratios, ply angles, stacking sequences, $L / D$ ratios, $T / D$ ratios, and composite materials in detail.

In contrast to existing studies, the novel features of this paper are as follows. First, this paper establishes a tapered composite boring bar model based on AMDM, which is an accurate numerical method. As far as we know, till now, there is no report about boring chatter suppression example using the AMDM. Second, we verify the effectiveness and the convergence of chatter stability about our AMDM model. These two kinds of verification make the analysis of this paper more complete. Third, the natural frequency and the cutting stability of our model are analyzed comprehensively. The results show that the natural frequency and the chatter stability of the tapered model can be improved by choosing appropriate taper ratio, ply angle, stacking sequences, $L / D$ ratio, $T / D$ ratio, and the carbon composite. The behavior characteristics and conclusions we gained in this paper are helpful to design high-quality composite boring bars, suppress chatter, achieve high-speed cutting in $\mathrm{CNC}$ boring, and finally improve production quality and efficiency.

The rest of this paper is developed as follows. In Section 2 , a tapered composite boring bar model is established. In Section 3, we first verify the effectiveness of the AMDM [32] by taking the ANSYS. And then, the natural frequencies of the composite boring bars with different ply angles, $L / D$ ratios, $T / D$ ratios, composite material types (three types), and taper ratios are analyzed in detail. In Section 4, the convergence of the chatter stabilities of tapered composite boring bar is verified at first. And then, the chatter stabilities of tapered composite boring bars for different ply angles, taper ratios, $L / D$ ratios, and $T / D$ ratios and for three types of composite materials are analyzed in detail. Section 5 concludes this paper.

\section{Modeling and Analysis of Tapered Boring Bar}

The model of the tapered boring bar is shown in Figure 1. The left side is fixed and the right side is free.

For the tapered boring bar, the equation of motion for transverse vibrations is as follows:

$$
\frac{\partial^{2}}{\partial z^{2}}\left(E I(z) \frac{\partial^{2} y(z, t)}{\partial z^{2}}\right)+\rho A(z) \frac{\partial^{2} y(z, t)}{\partial t^{2}}=0,
$$

where $E$ is Young's modulus, $I(z)$ is the second moment of area, $A(z)$ is the cross-sectional area at the position $z$, $\rho$ is the mass density of the boring bar material, and $y(z, t)$ is the transverse deflection at time $t$.

The transverse deflection $y(z, t)$ can be written as follows:

$$
y(z, t)=Y(z) h(t),
$$

where $Y(z)$ is the transverse deflection and $h(t)$ is a harmonic function of time. If $\omega$ denotes the frequency of $h(t)$, then 


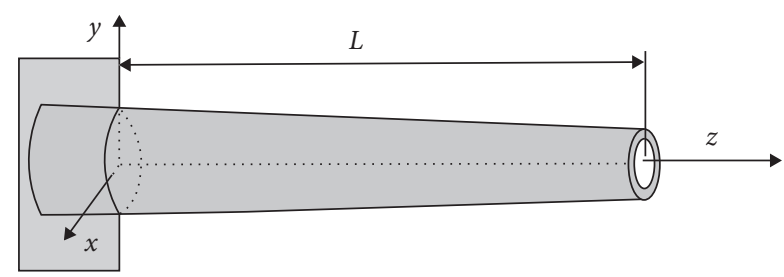

FIGURE 1: Model of tapered composite boring bar.

$$
\frac{\partial^{2} y(z, t)}{\partial t^{2}}=-\omega^{2} Y(z) h(t)
$$

where $\omega$ is the circular frequency of $h(t)$

By substituting (3) into (1), we obtain

$$
\frac{\partial^{2}}{d z^{2}}\left(E I(z) \frac{d^{2} Y(z)}{d z^{2}}\right)-\rho A(z) \omega^{2} Y(z)=0 .
$$

Based on Figure 1, the boundary conditions at $z=0$ point (i.e., the fixed end) are defined as follows:

$$
\begin{gathered}
\left.Y(0)\right|_{z=0}=0, \\
\left.\frac{d Y(z)}{d z}\right|_{z=0}=0 .
\end{gathered}
$$

The boundary conditions at $z=L$ point (i.e., the free end, at which the bending moment and the shear force are zero) are defined as follows:

$$
\begin{array}{r}
\left.\frac{d^{2} Y(z)}{d z^{2}}\right|_{z=L}=0, \\
\left.\frac{d}{d z}\left[E I(z) \frac{d^{2} Y(z)}{d z^{2}}\right]\right|_{z=L}=0 .
\end{array}
$$

The radius of the fixed end (i.e., $z=0)$ is $R_{0}$. The radius of the free end (i.e., $z=L$ ) is $R_{L}$, and the radius ratio is defined as follows:

$$
\alpha=\frac{R_{L}}{R_{0}}
$$

where $\alpha$ denotes the taper ratio. When $\alpha=1$, the model reduces to the uniform cross-section composite boring bar model.

Assuming that the cross-sectional radius of the composite boring bar is linearly distributed along the $z$-axis, the radius at any $z$ position is as follows:

$$
R(z)=R_{0}\left[1+(\alpha-1) \frac{z}{L}\right]
$$

The tapered mass and the bending stiffness of the composite bar are as follows:

$$
\begin{aligned}
& \rho A(z)=\rho A_{0}\left[1+(\alpha-1) \frac{z}{L}\right]^{2}=\rho A_{0}\left[1-\beta \frac{z}{L}\right]^{2}, \\
& E I(z)=E I_{0}\left[1+(\alpha-1) \frac{z}{L}\right]^{4}=E I_{0}\left[1-\beta \frac{z}{L}\right]^{4},
\end{aligned}
$$

where $\beta=1-\alpha$.
By substituting (10) and (11) into (1), we obtain the equation of motion for a tapered boring bar:

$$
\frac{d^{2}}{d z^{2}}\left(\left[1-\beta \frac{z}{L}\right]^{4} \frac{d^{2} Y(z)}{d z^{2}}\right)-\frac{\rho A_{0} \omega^{2}}{E I_{0}}\left[1-\beta \frac{z}{L}\right]^{2} Y(z)=0 .
$$

By substituting (11) into (7), we obtain the boundary condition:

$$
\left.\left[\frac{d^{3} Y(z)}{d z^{2}}-\frac{4 \beta}{(1-\beta) L} \frac{d^{2} Y(z)}{d z^{2}}\right]\right|_{z=L}=0
$$

The following dimensionless quantities are defined:

$$
\begin{aligned}
Z & =\frac{z}{L}, \\
Y(Z) & =\frac{Y(z)}{L}, \\
\Omega^{2} & =\frac{\rho A_{0} \omega^{2} L^{4}}{E I_{0}} .
\end{aligned}
$$

Equation (12) can be rewritten in dimensionless form as follows:

$$
\frac{d^{2}}{d Z^{2}}\left((1-\beta Z)^{4} \frac{d^{2} Y(Z)}{d Z^{2}}\right)-\Omega^{2}(1-\beta Z)^{2} Y(Z)=0
$$

Equation (15) can be expanded as follows:

$$
\begin{aligned}
& \frac{d^{4} Y(Z)}{d Z^{4}}-\frac{8 \beta}{1-\beta Z} \frac{d^{3} Y(Z)}{d Z^{3}}+\frac{12 \beta^{2}}{(1-\beta Z)^{2}} \frac{d^{2} Y(Z)}{d Z^{2}} \\
& -\frac{\Omega^{2}}{(1-\beta Z)^{2}} Y(Z)=0 .
\end{aligned}
$$

At the position $z=1$, the boundary conditions of (6) and (13) can be rewritten as

$$
\begin{aligned}
Y^{\prime \prime}(1) & =0, \\
Y^{\prime \prime \prime}(1)-4 \frac{\beta}{1-\beta} Y^{\prime \prime}(1) & =0 .
\end{aligned}
$$

$Y(Z)$ can be determined by the AMDM [32]. Based on the AMDM, (16) can be expressed in the following form:

$$
\begin{aligned}
Y(Z)= & \Phi(Z)+L^{-1}\left\{\frac{8 \beta}{1-\beta Z} \frac{d^{3} Y(Z)}{d Z^{3}}-\frac{12 \beta^{2}}{(1-\beta Z)^{2}} \frac{d^{2} Y(Z)}{d Z^{2}}\right. \\
& \left.+\frac{\Omega^{2}}{(1-\beta Z)^{2}} Y(Z)\right\},
\end{aligned}
$$

where

$$
\Phi(Z)=Y(0)+Y^{\prime}(0) Z+\frac{Y^{\prime \prime}(0)}{2} Z^{2}+\frac{Y^{\prime \prime \prime}(0)}{6} Z^{3} .
$$

By substituting (20) into (19), $Y(Z)$ can be simply expressed by a sum of $Z$ functions: 


$$
\begin{aligned}
Y(Z)= & \sum_{k=0}^{n} C_{k} Z^{k}=Y(0)+Y^{\prime}(0) Z+\frac{Y^{\prime \prime}(0)}{2} Z^{2} \\
& +\frac{Y^{\prime \prime \prime}(0)}{6} Z^{3}+C_{k} Z^{k},
\end{aligned}
$$

where $C_{k}=(1 /(k(k-1)(k-2)(k-3))) \sum_{j=0}^{k-4}[8(j+3)(j+$ 2) $(j+1) \beta^{k-j-3} C_{j+3}+\lambda(k-j-3) \beta^{k-j-4} C_{j}-12(k-j-3)$ $\left.(j+2)(j+1) \beta^{k-j-2} C_{j+2}\right]$.

Based on the boundary conditions of the boring bar, the initial coefficients are determined as follows:

$$
\begin{aligned}
& C_{0}=0, \\
& C_{1}=0, \\
& C_{2}=\frac{Y^{\prime \prime}(0)}{2}, \\
& C_{3}=\frac{Y^{\prime \prime \prime}(0)}{6} .
\end{aligned}
$$

Substituting these coefficients into (21), we obtain an equation in terms of three variables, that is, $C_{2}, C_{3}$, and $\Omega$. Substituting (21) into the boundary equations at $z=1$ (see [17] and [18]) and solving the two variables $C_{2}$ and $C_{3}$, we can obtain the following equation:

$$
f_{r 0}^{[n]}(\Omega) C_{2}+f_{r 1}^{[n]}(\Omega) C_{3}=0, \quad r=1,2 .
$$

It is assumed that $C_{2}$ and $C_{3}$ are not equal to zero at the same time. According to Cramer's rule,

$$
\left|F^{[n]}(\Omega)\right|=0 .
$$

The dimensionless natural frequency $\Omega$ corresponding to $n$ terms is calculated using (24), and the $\Omega$ value is determined by the following equation:

$$
\left|\Omega_{i}^{[n]}-\Omega_{i}^{[n-1]}\right| \leq \varepsilon
$$

where $\varepsilon$ is a small preset value used to control the accuracy. Substituting $\Omega$ into the third equation of (16), we obtain the natural frequency of the tapered boring bar as follows:

$$
\omega_{1}=\Omega \sqrt{\frac{E I_{0}}{\rho A_{0} L^{4}}} .
$$

\section{Effect of Taper Ratios on the Natural Frequency of Composite Boring Bar}

3.1. Effectiveness of the AMDM. As the AMDM was commonly applied to solve linear and nonlinear initial/boundary-value problems in physics [32], it is needed to verify whether the AMDM works in calculating the natural frequency of composite tapered boring bar. To realize this aim, we select ANSYS (which is a finite element analysis software) to solve the boring bar frequency because of the popularity of it in modeling various kinds of beams. In modeling process, we first use ANSYS 15.0 to create a composite tapered boring bar model. And then, we make the following settings. We select the "SHELL 281" as the element type and choose the carbon fiber as the composite material. In addition, we set 8 layers and the thickness of each layer is $0.00025 \mathrm{~m}$. The stacking sequences are denoted as $[\theta]_{8}$. Finally, we assign the length of the tapered boring bar with $0.2 \mathrm{~m}$, the inner diameter with $0.016 \mathrm{~m}$, and the outer diameter with $0.02 \mathrm{~m}$. The mechanical properties of the carbon fiber are listed in Table 1 . The resulting tapered composite boring bar model after being meshed is shown in Figure 2.

In the analysis about natural frequencies of the tapered composite boring bar which are generated using the ANSYS software, 7 taper ratios ranging from 0.3 to 0.9 are selected. The resulting 7 natural frequencies are filled into the third row of Table 2. Under the same parameters and taper ratios, the AMDM is used to solve the natural frequencies of composite boring bar model. The results are filled into the second row of Table 2. The difference between the natural frequencies (i.e., (the value of the 2 nd row-the value of the 3 rd row)/the value of the 2 nd row*100) of these two methods is calculated and added as the fourth row of Table 2.

From Table 2, we can see that the natural frequencies computed by the ANSYS are relevant to the taper ratios. The smaller the taper ratio is, the greater the natural frequency is. Similar rule is obtained by the AMDM. In particular, the natural frequency obtained by the ANSYS is correspondingly smaller than the one that is obtained by the AMDM. However, all the differences are within $10 \%$, which is acceptable. Therefore, the AMDM can be used to solve the natural frequencies of composite boring bar under different taper ratios.

\subsection{Effect of Ply Angle on the Natural Frequency of the Tapered} Composite Boring Bar. To study the effect of different ply angles on the natural frequency of the tapered composite boring bar, three ply angles such as $0^{\circ}, 45^{\circ}$, and $90^{\circ}$ were set. Keeping the diameter of the fixed end $(z=0)$ of the boring bar constant, we change the diameter of the free end $(z=L)$ gradually based on the taper ratio. The natural frequency curves for the three different ply angles and different taper ratios are shown in Figure 3. The horizontal axis is the taper ratio. The vertical axis is the natural frequency. For the tapered composite boring bar, the curve of the ply angle $0^{\circ}$ is at the top, the curve of the ply angle $45^{\circ}$ is in the middle, and the curve of the ply angle $90^{\circ}$ is at the bottom. The natural frequency of each curve decreased with the increase in the taper ratio. Thus, the smaller the ply angle and the smaller the taper ratio, the higher the natural frequency.

3.3. Effect of $L / D$ Ratio on Natural Frequency of the Tapered Composite Boring Bar. To analyze the effect of the $L / D$ $\left(D=R_{0}\right)$ ratio on the natural frequency of the tapered composite boring bar, the ply angle is set to $45^{\circ}$. The $L / D$ ratio is set to $7.5,10$, and 12.5 . The other parameters are set to the same values as those in Section 3.1. The effect of the L/ $D$ ratio on the natural frequency versus taper ratio curves is shown in Figure 4. The horizontal axis is the taper ratio. The vertical axis is the natural frequency. The natural frequency curves of the tapered composite boring bar are different 
TABLE 1: Mechanical parameters of three composite materials.

\begin{tabular}{lccccccc}
\hline Parameters & $E_{1}(\mathrm{GPa})$ & $E_{2}=E_{3}(\mathrm{GPa})$ & $G_{12}(\mathrm{GPa})$ & $G_{23}=G_{31}(\mathrm{GPa})$ & $\nu_{21}=\nu_{31}$ & $\nu_{32}$ & $\rho\left(\mathrm{Kg} / \mathrm{m}^{3}\right)$ \\
\hline Carbon & 181.0 & 10.3 & 7.17 & 3.78 & 0.28 & 0.30 \\
Aramid & 76 & 11.5 & 6.3 & 4.4 & 0.30 & 0.34 & 1760 \\
Glass & 45 & 10 & 5 & 3.8 & 0.30 & 0.40 \\
\hline
\end{tabular}

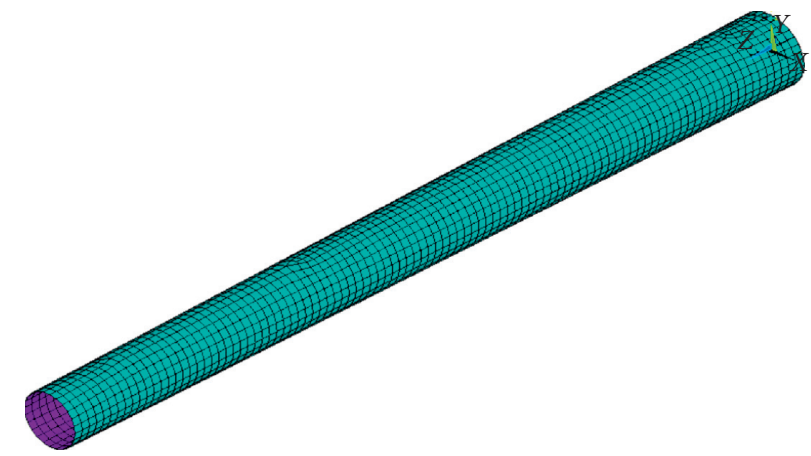

FIGURE 2: Finite element model of the tapered composite boring bar.

TABLE 2: Comparison of natural frequencies obtained by the AMDM and the ANSYS.

\begin{tabular}{lccccccc}
\hline Taper ratio & 0.3 & 0.4 & 0.5 & 0.6 & 0.7 & 0.8 & 0.9 \\
\hline AMDM (Hz) & 6737 & 6436 & 6247 & 6105 & 5990 & 5895 & 5814 \\
ANSYS (Hz) & 6645 & 6254 & 5969 & 5744 & 5557 & 5395 \\
Difference (\%) & 1.4 & 2.8 & 4.5 & 5.9 & 7.2 & 5253 \\
\hline
\end{tabular}

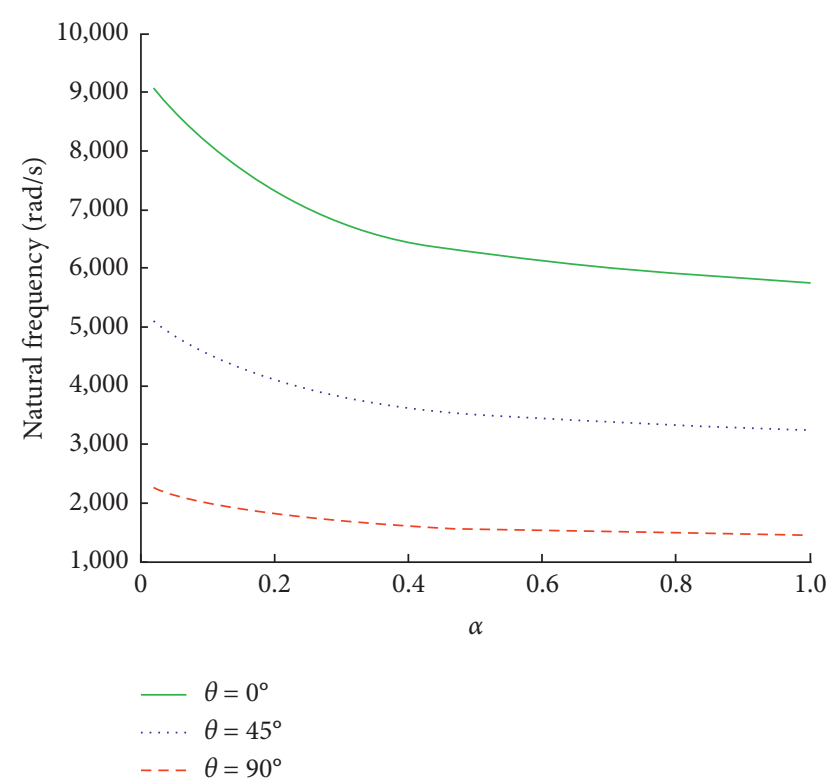

FIGURE 3: Natural frequency of the tapered composite boring bar with different ply angles.

for different $L / D$ ratios. The natural frequency curve for the $L / D=7.5$ is at the top, the curve for $L / D=10$ is in the middle, and the curve for $L / D=12.5$ is at the bottom. The three natural frequency curves decreased with the increase of the taper ratio. Moreover, they decrease with the $L / D$ ratio increase.

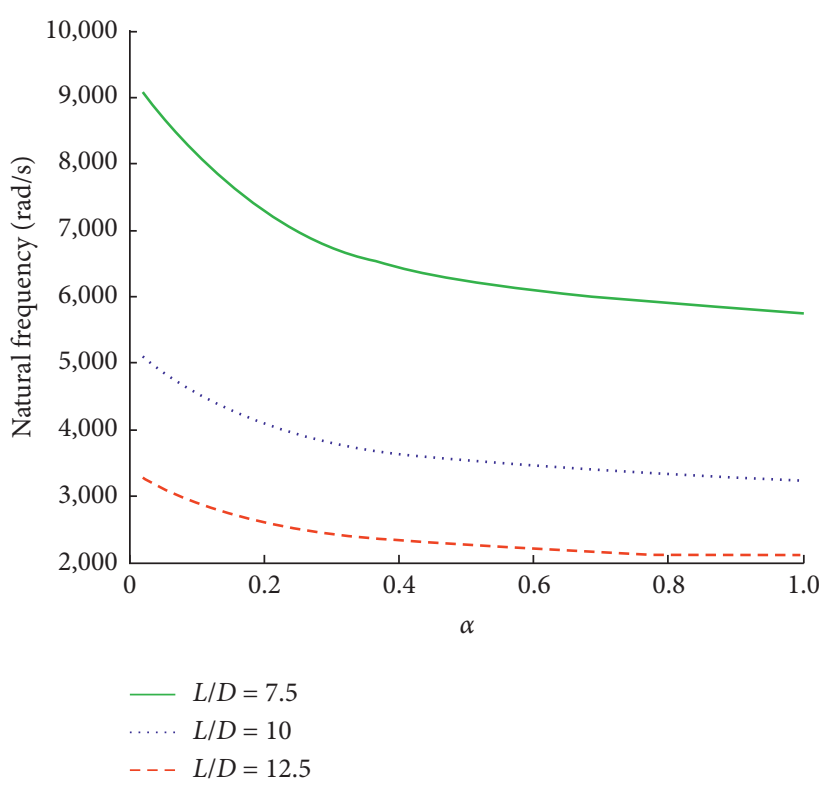

FIGURE 4: Natural frequency of the tapered composite boring bar with different $L / D$ ratios.

3.4. Effect of $T / D$ Ratios on the Natural Frequency of the Tapered Composite Boring Bar. To analyze the effect of the $T / D\left(D=R_{0}\right)$ ratio on the natural frequency of the tapered composite boring bar, the inner diameter was fixed, and the outer diameter is varied by adding more layers. Three numbers of layers (i.e., 4, 8, and 12) are set. The corresponding 
$T / D$ ratio values are $0.005,0.01$, and 0.15 , respectively. The other parameters are set as same as those in Section 3.1. The natural frequency versus taper ratio curves for different $T / D$ ratios is shown in Figure 5. The horizontal axis is the taper ratio. The vertical axis is the natural frequency. When the $T / D$ ratio is 0.015 , the curve is at the top. When the $T / D$ ratio is 0.005 , the curve is at the bottom. When the $T / D$ ratio is 0.01 , the curve is in the middle. The natural frequency decreased with the increase of the taper ratio and increase of the $T / D$ ratio.

3.5. Effect of Different Composite Materials on Natural Frequency of the Tapered Composite Boring Bar. To analyze the effect of the type of composite material on the natural frequency of the tapered composite boring bar, three types (carbon fiber, aramid, and glass fiber) of composite materials are selected. The mechanical parameters of the three composite materials are listed in Table 1 . The other parameters are set to the same values as those in Section 3.1. The natural frequency curves for different composite materials versus taper ratio are shown in Figure 6. The horizontal axis is the taper ratio. The vertical axis is the natural frequency. The natural frequency curve of the tapered carbon fiber composite material boring bar is at the top, followed by Aramid fiber composite and the glass fiber composite curves. The natural frequency of the tapered boring bar decreased with the increase in the taper ratio for all the materials. Thus, carbon fiber composite is the best choice of the three composite materials.

\section{Chatter Stability of the Tapered Composite Boring Bar}

To analyze the chatter stability of the tapered composite boring bar, we deduce the equations of the cutting depth and the spindle speed of a one-degree-of-freedom system as follows [33]:

$$
\begin{aligned}
b_{\lim } & =\frac{2 \zeta \omega_{1} \omega_{c} M}{K_{c} \sin \left(2 \arctan \left(\left(2 \zeta \omega_{1} \omega_{c}\right) /\left(\omega_{c}^{2}-\omega_{1}^{2}\right)\right)\right)}, \\
n & =\frac{60 \omega_{c}}{(2 m+1) \pi+2 \arctan \left(\left(2 \zeta \omega_{1} \omega_{c}\right) /\left(\omega_{c}^{2}-\omega_{1}^{2}\right)\right)}, \quad m=0,1,2,
\end{aligned}
$$

where $b_{\text {lim }}$ is the critical cutting depth, $n$ is the spindle speed, $M=\int_{0}^{l} \rho A Y_{i}^{2}(z) d z$ is the mass of the boring bar, $\omega_{c}$ is the chatter frequency of the boring bar in the critical stable state, $\omega_{1}$ is the first natural frequency of the boring bar, $\zeta$ is the damping coefficient of the boring bar, and $K_{c}$ is the coefficient of the cutting force $\left(\mathrm{N} / \mathrm{mm}^{2}\right)$.

4.1. Convergence of Chatter Stability of the Tapered Composite Boring Bar. The natural frequency of $\omega_{1}$ was calculated by the AMDM. As the AMDM uses $k$ terms to form an approximate solution, it must be determined whether the approximation affects the accuracy of the results of chatter stability. For example, Abbaoui and Cherruault [34] used the AMDM to study the convergence of a nonlinear equation. In

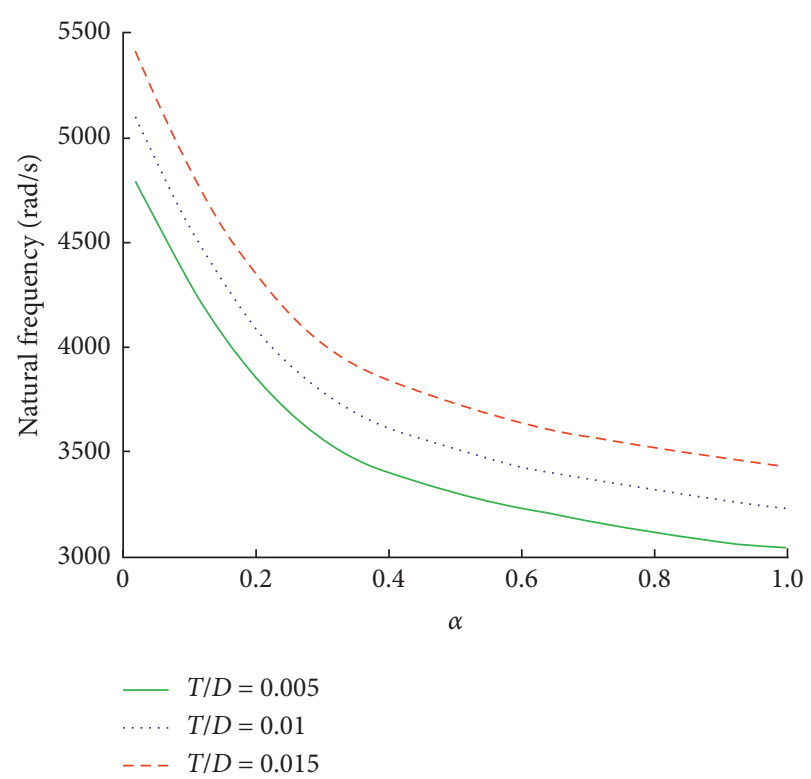

FIGURE 5: Natural frequency of the tapered composite boring bar with different $T / D$ ratios.

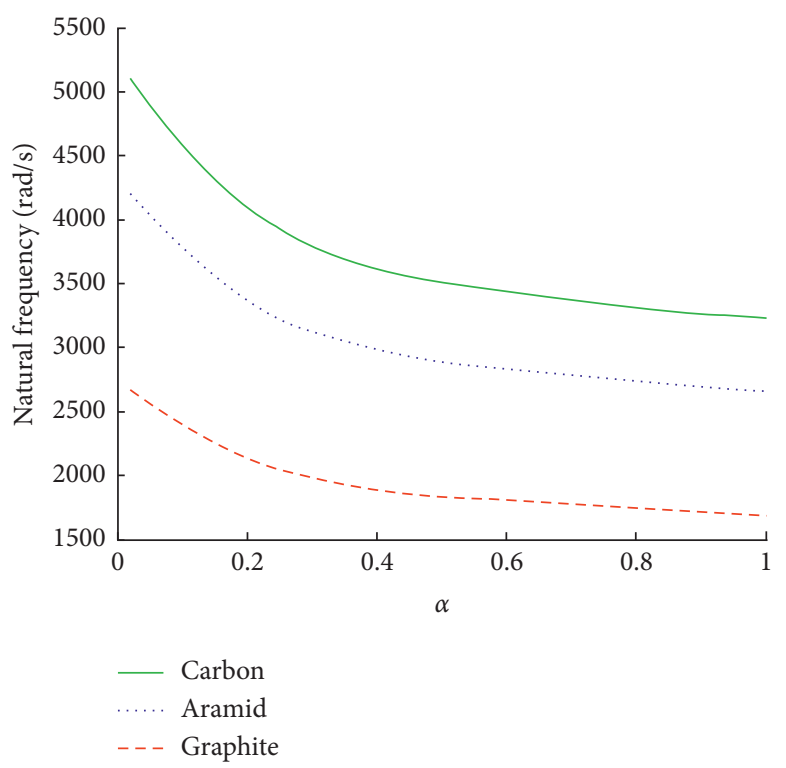

FIGURE 6: Natural frequency of the tapered composite boring bar with different composite material.

this study, the accuracy is controlled using (25). To achieve a precision of $\varepsilon=0.00001$, the natural frequency is calculated using the first 23 items. To verify the accuracy, the cutting stability curves are calculated using the first 11, 14, 17, and 20 terms for comparison. If the cutting stability curves found using $k$ terms overlapped with the curve found using 23 terms, this value of $k$ is sufficient to achieve the desired accuracy. Figure 7 shows only two chatter stability lobes. When $k$ is 14,17 , and 20 , the curves are overlapped with the curve of $k=23$. Thus, the $k=23$ approximation is sufficiently accurate. To further distinguish the small differences between the approximations, the ultimate cutting depth is 


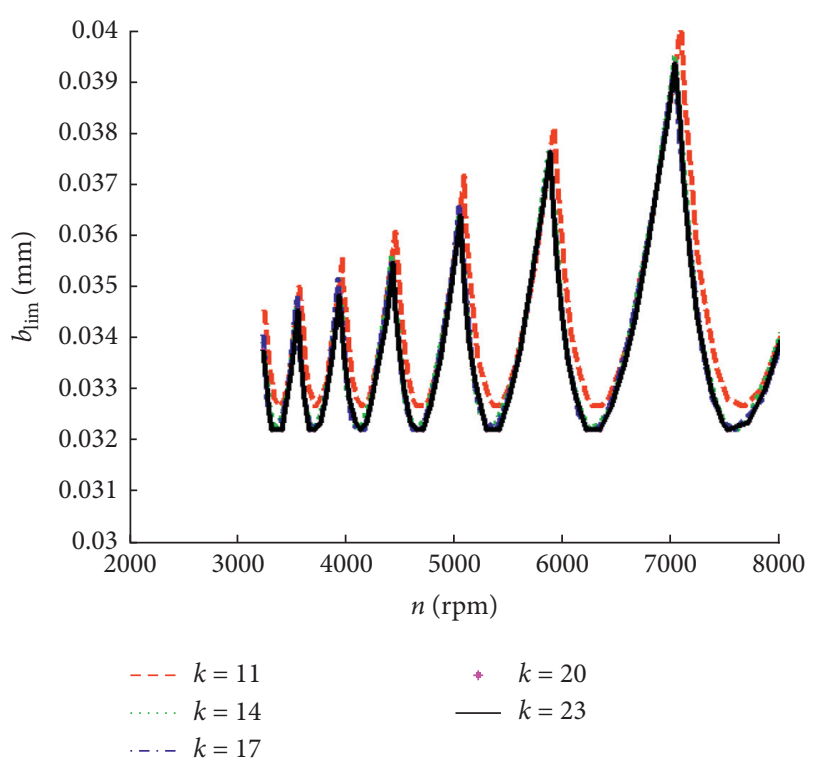

Figure 7: Different approximate numbers of terms effect on chatter stability.

calculated and compared. The results are listed in Table 3. The first row lists the number of items. The second row is the limit cutting depth $\left(V_{k}\right)$. The third row is the difference between $V_{k}$ and $V_{23}$.

As shown, the limit cutting depth obtained when $k=23$ is chosen as the baseline. The difference of the ultimate cutting depth is 0.00046656 when $k=11$ and 0.00000002 when $k=14$, respectively. Thus, when $k=14$, the cutting depth completely meets the precision need (i.e., $\varepsilon \leq 0.00001$ ). In particular, when $k=17$ and 20 , the cutting depth is close to 0 . Therefore, we can select the first 23 items. The results listed in Table 3 and the curves drawn in Figure 7 are consistent with the analysis results. From these results, we can conclude that the AMDM is convergent.

4.2. Effect of Taper Ratio on the Chatter Stability. To analyze the effect of the taper ratio on the chatter stability, four different taper ratios such as $0.3,0.5,0.7$, and 1.0 are selected. The other parameters of the tapered boring bar are set as the same as those in Section 3.1. The material of the tapered boring bar is the carbon composite. The length is $0.2 \mathrm{~m}$, the inner diameter is $0.016 \mathrm{~m}$, and the outer diameter is $0.02 \mathrm{~m}$. The ply angle is $45^{\circ}$. The chatter stability lobes of four taper ratios are shown in Figure 8.

Figure 8 shows that, for different taper ratios, the chatter stability curves are different. When the taper ratio is 0.3 , the lobe curve is at the top, and when the taper ratio is 1.0 , the lobe curve is at the bottom. There are two chatter curves in the middle, and the curve with a taper ratio of 0.5 is above that for a taper ratio of 0.7 . It can be concluded that a smaller taper ratio yielded higher chatter stability.

4.3. The Effect of Ply Angle on the Chatter Stability. To analyze the effect of ply angle on the chatter stability of the tapered composite boring bar, three different ply angles such as $0^{\circ}$, $45^{\circ}$, and $90^{\circ}$ are set. To compare the effect of the taper ratio on the chatter stability of the tapered composite boring bar, a taper ratio of 0.7 is selected to compare with the uniform cross-section bar (taper ratio $=1.0$ ). To distinguish them, the lobe curves are plotted using different line types. The subscript $T$ indicates the tapered composite boring bar (taper ratio $=0.7$ ), and the subscript $U$ indicates a uniform crosssection composite boring bar (taper ratio $=1.0$ ). The lobe curves of these two boring bar models with three different ply angles are shown in Figure 9.

Figure 9 shows that the chatter stability curves are different for different ply angles and taper ratios. For the same taper ratio, when the ply angle is $0^{\circ}$, the curve is at the top. When the ply angle is $90^{\circ}$, the curve is at the bottom, and when the ply angle is $45^{\circ}$, the curve is in the middle. Moreover, for the same ply angle, the curve for the smaller taper ratio is at the top. The distance between the chatter stability curves is large when the ply angle is $0^{\circ}$. When the ply angle is $90^{\circ}$, the two curves almost overlapped. Thus, the smaller the ply angle and taper ratio, the more stable the chatter.

\subsection{Effect of Stacking Sequences on the Chatter Stability.} To analyze the chatter stability of the tapered boring bar under different stacking sequences, four different stacking sequences are designed. Each stacking sequence consisted of eight layers, including four $0^{\circ}$ layers, two $45^{\circ}$ layers, and two $90^{\circ}$ layers. The detailed stacking sequences are listed in Table 4 . The chatter stability curves of four different stacking sequences and two taper ratios are shown in Figure 10.

Figure 10(a) shows that, for different stacking sequences and different taper ratios, the chatter stability curves are different. Figure 10(b) shows an enlarged section (section highlighted by a dashed rectangle in Figure 10(a)) of the lobe curves. For different taper ratios, the lobe curve with a small taper ratio is at the top, whereas the lobe curve with a large taper ratio is at the bottom. For the same taper ratio with different stacking sequences, the lobe curves of different stacking sequences are different. Figure 10(b) shows that the chatter stability curve of the 1st stacking sequence is at the top, and that of the 3rd stacking sequence is at the bottom. In between these two curves, the curve of 4 th stacking sequence is higher than the one of the 2 nd stacking sequence. The ultimate cutting depths are listed in Table 4. The order of the ultimate cutting depths from largest to smallest for the different stacking sequences is 1 st, 4 th, 2 nd, and 3 rd, which is consistent with the results shown in Figure 10(b). Therefore, the 1st stacking sequence of the chatter stability of the tapered composite boring bar is the best one.

4.5. Effect of L/D Ratio on Chatter Stability. To compare the $L / D$ ratios on the effect of the tapered boring bar chatter stability, the boring bar length is set to $0.25,0.2$, and $0.15 \mathrm{~m}$. The corresponding $L / D$ ratio of the tapered boring bar is assigned with $7.5,10$, and 12.5 , respectively. The inner and outer diameters, ply angles, and ply sequences of the boring bar are set to the same values as those illustrated in Section 4.2. The lobe curves are shown in Figure 11. 
TABLE 3: Effect of number of terms on prediction accuracy.

\begin{tabular}{|c|c|c|c|c|c|}
\hline Number terms & $k=11$ & $k=14$ & $k=17$ & $k=20$ & $k=23$ \\
\hline$V_{k}$ & 0.03265941 & 0.03219287 & 0.03219285 & 0.03219285 & 0.03219285 \\
\hline$\left|\hat{V}_{k}-V_{23}\right|$ & 0.00046656 & 0.00000002 & 0 & 0 & 0 \\
\hline
\end{tabular}

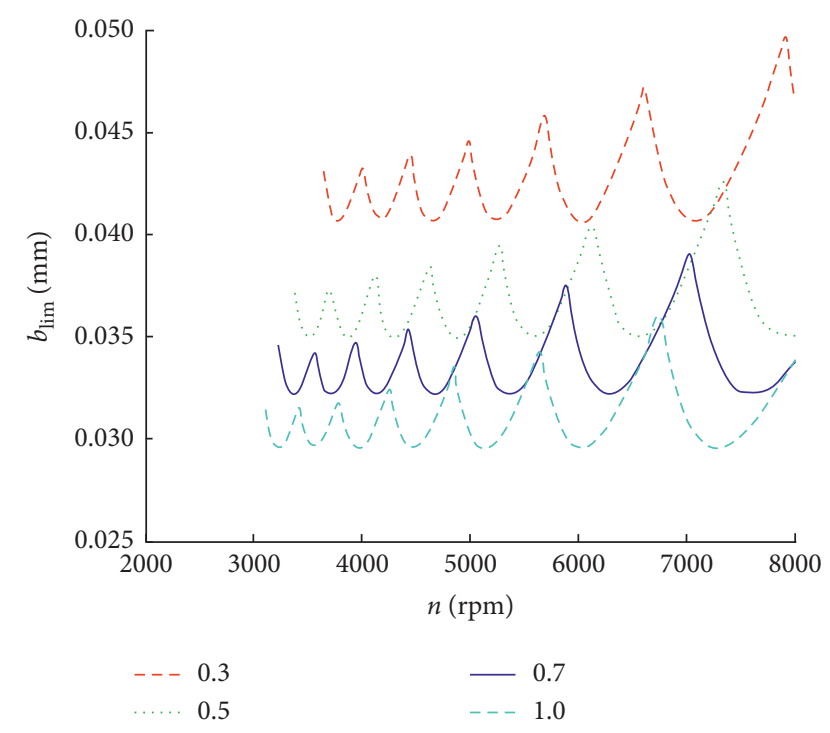

FIGURE 8: Effect of the taper ratio on chatter stability.

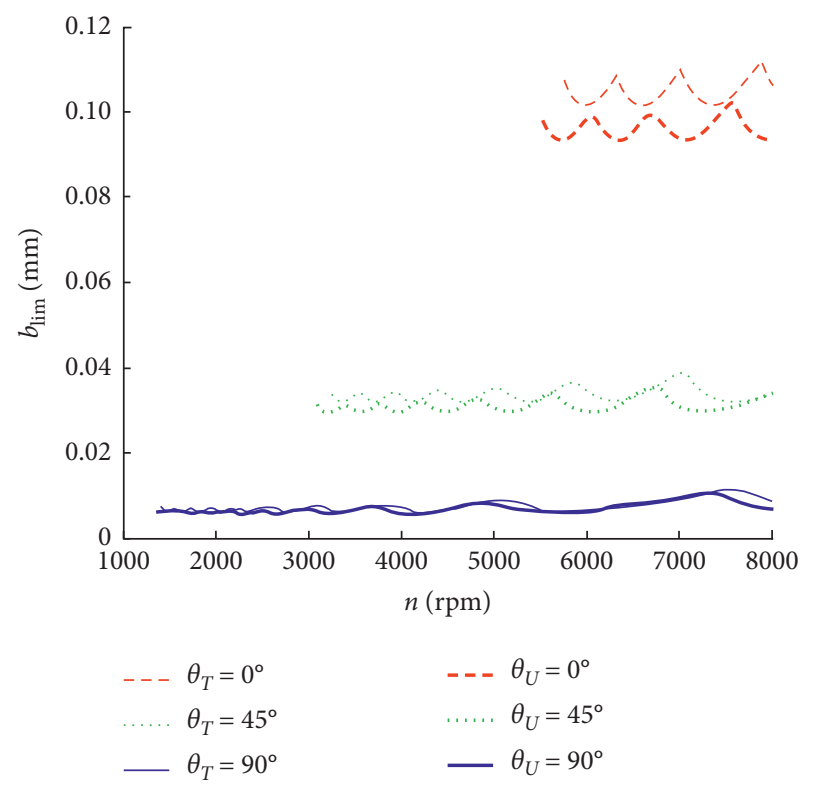

FIgURE 9: Effect of the ply angle on chatter stability.

Figure 11 shows that the chatter stability curves are different for different $L / D$ ratios and different taper ratios. For the same taper ratio, when the $L / D$ ratio is 7.5 , the chatter stability curve is at the top. When the $L / D$ ratio is 10 , the chatter stability curve is in the middle. When the $L / D$ ratio is 12.5 , the chatter stability curve is at the bottom. For the same $L / D$ ratios with different taper ratios, the small taper ratio curve lies at the top, and the large taper ratio curve lies at the bottom. Moreover, when the $L / D$ ratio is small, the
TABle 4: Comparison of the ultimate cutting depth of different stacking sequences.

\begin{tabular}{|c|c|c|c|}
\hline \multirow[b]{2}{*}{ Number } & \multirow[b]{2}{*}{ Stacking sequence } & \multicolumn{2}{|c|}{ Ultimate cutting depth } \\
\hline & & $\begin{array}{l}\text { Uniform } \\
\text { (mm) }\end{array}$ & $\begin{array}{c}\text { Tapered } \\
(\mathrm{mm})\end{array}$ \\
\hline 1 st & {$[45,0,45,0,90,0,90,0]$} & 0.05621762 & 0.06113990 \\
\hline 2nd & {$[0,0,45,45,90,90,0,0]$} & 0.05544041 & 0.06023316 \\
\hline $3 \mathrm{rd}$ & {$[90,45,0,0,0,0,45,90]$} & 0.05518135 & 0.05997409 \\
\hline 4 th & {$[0,0,90,45,45,90,0,0]$} & 0.05595855 & 0.06088083 \\
\hline
\end{tabular}

distance between the two curves is large. On the contrary, when the $L / D$ ratio is large, the distance between the two curves is small. Thus, we can conclude that the smaller the taper ratio and $L / D$ ratio, the better the chatter stability.

4.6. Effect of T/D Ratios on Chatter Stability. To study the chatter stability of the tapered composite boring bar for different $T / D$ ratios, the number of layers is set to 4,8 , and 12 , respectively. The corresponding $T / D$ ratios are 0.005 , 0.01 , and 0.15 , respectively. The other parameters, such as length, ply angles, and inside diameter, are set to the same values as those in Section 4.2. The chatter stability curves for different $T / D$ ratios are shown in Figure 12.

Figure 12 shows that the chatter stability is different for different $T / D$ and taper ratios. For the same taper ratio, when $T / D$ is 0.05 , the chatter stability curve is at the bottom. When the $T / D$ ratio is 0.1 , the chatter stability curve is in the middle. When the $T / D$ ratio is 0.15 , the chatter stability curve is at the bottom. For the same $T / D$ ratio, the chatter stability curve with the smallest taper ratio is at the top, and the chatter stability curve with large taper ratio is at the bottom. When the $T / D$ ratio is large, the distance between the chatter stability curves is large, while when the $T / D$ ratio was small, the chatter stability curves almost overlapped. Therefore, the larger the $T / D$ ratio and the smaller the taper ratio, the better the chatter stability.

4.7. Effect of Different Composite Materials on Chatter Stability. To compare the chatter stability of tapered boring bars with different composite materials, three types of composite materials such as carbon, aramid, and glass are selected. The mechanical parameters of the three composite materials are listed in Table 1. The ply angles, length, and other parameters are assigned with the same values as those illustrated in Section 4.2. The resulting lobe curves for the three different composites materials are shown in Figure 13.

Figure 13 shows that different composite materials and taper ratios produced different chatter stabilities. The chatter stability curve of the carbon fiber composite boring bar is at the top, the chatter stability curve of the aramid composite boring bar is in the middle, and the chatter stability curve of the glass fiber composite boring bar is at the bottom. For the 


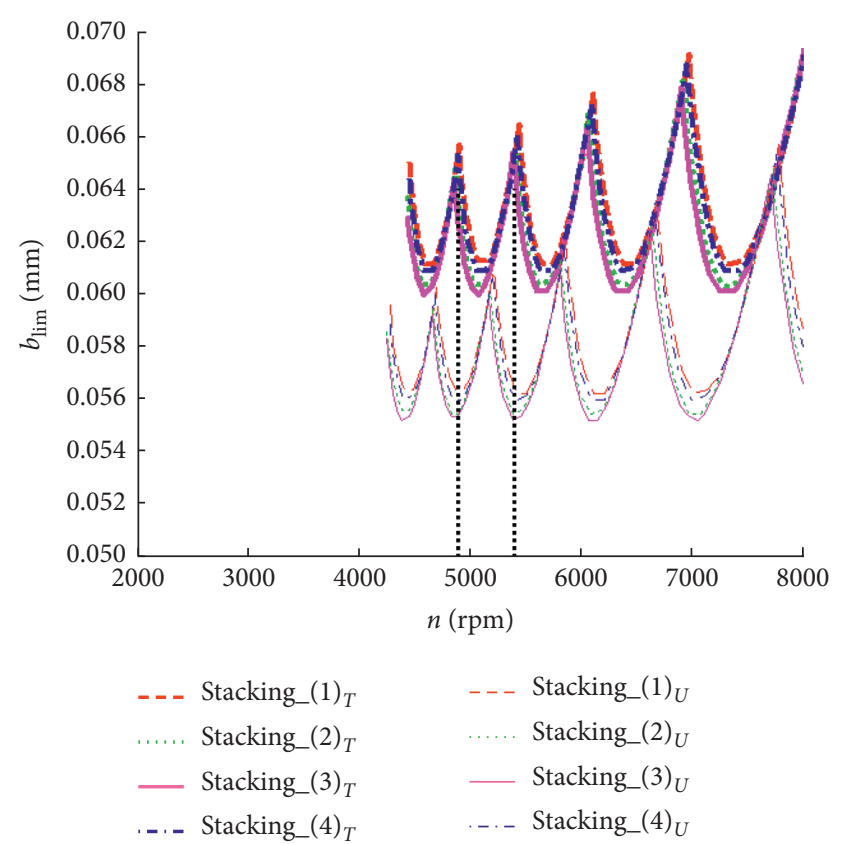

(a)

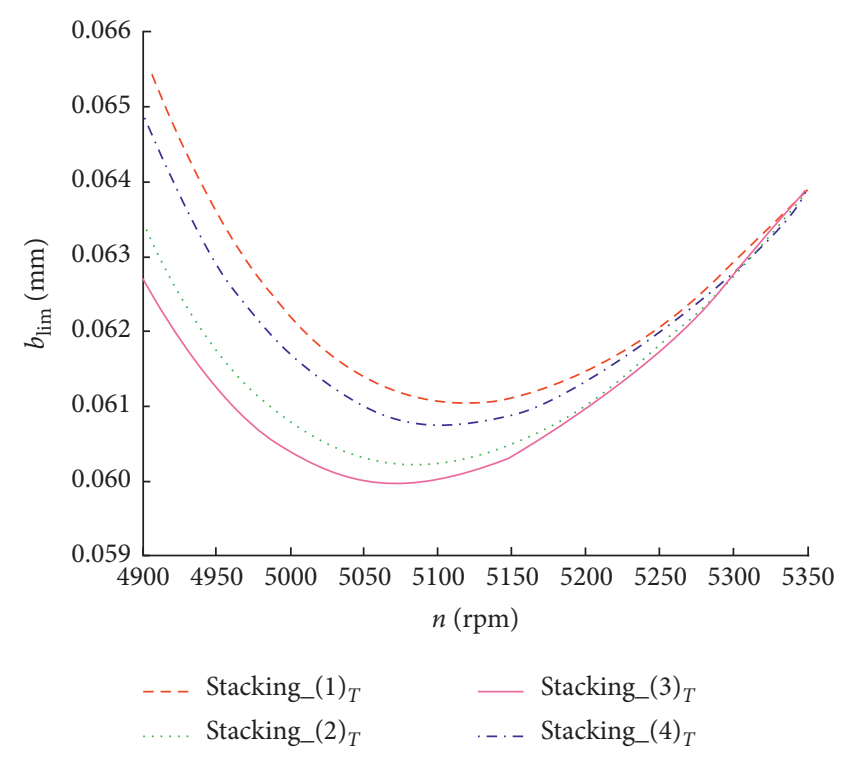

(b)

FIgURE 10: Effect of the stacking sequence on chatter stability.

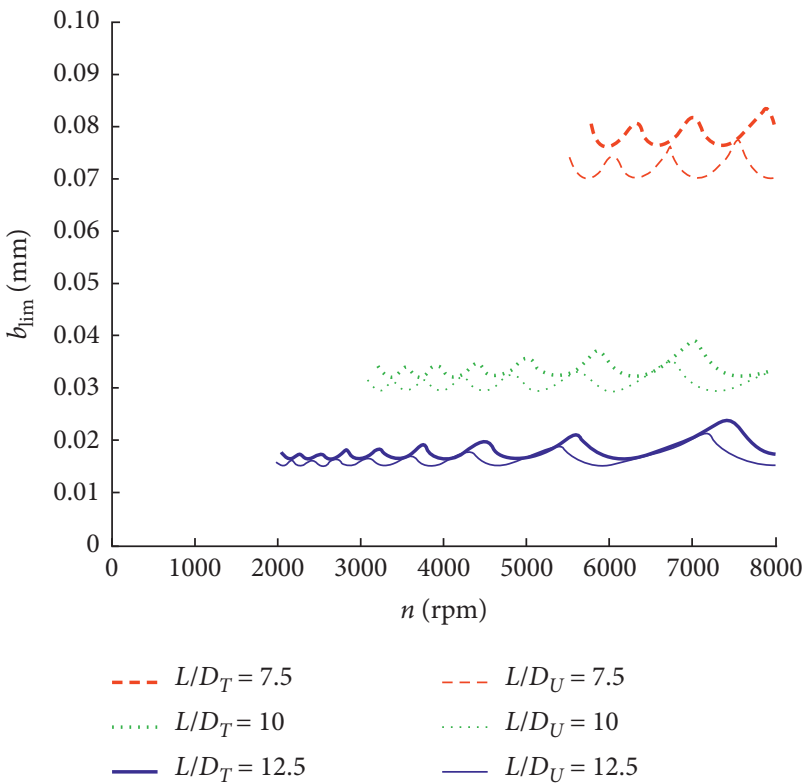

Figure 11: Effect of the $L / D$ ratio on the chatter stability.

same composite material, the chatter stability curve with the smallest taper ratio is at the top, and that with the largest taper ratio is at the bottom. Therefore, it can be concluded that the chatter stability of the carbon fiber composite material is the best one.

4.8. Discussion. Although smaller taper ratios can improve the chatter stability, in boring process, the taper ratios cannot be too small. Szuba et al. [35] found that a hollow

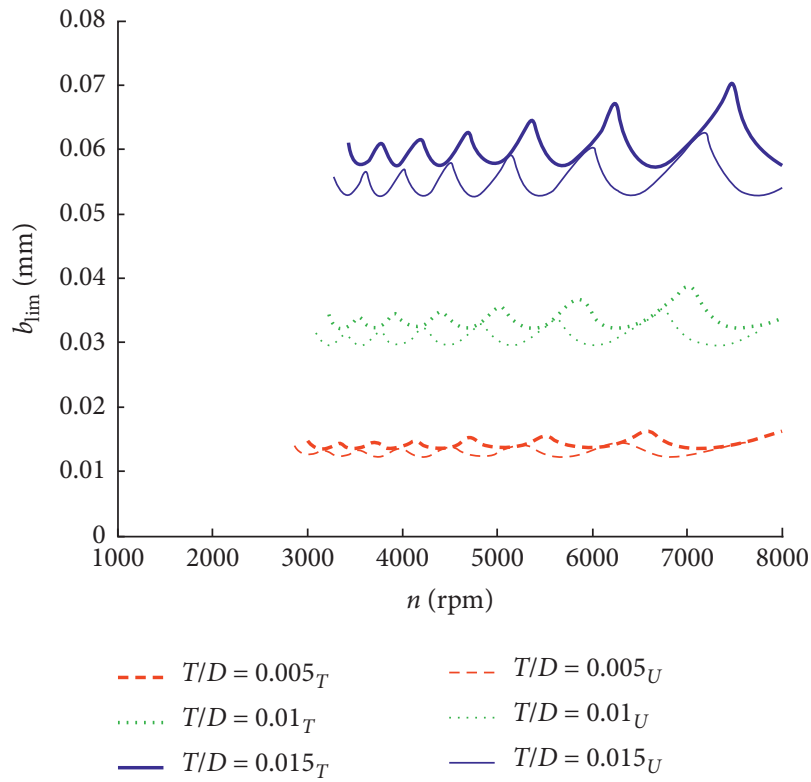

FIgURE 12: Effect of the $T / D$ ratio on chatter stability.

boring bar had a better bending stiffness and natural frequency when the taper ratio was 0.6733 . In particular, if the taper ratio is too small, larger holding cutter tools are needed. Moreover, if the transverse cutting force is the same, the deformation of a small taper ratio boring bar will be larger than that of a uniform cross-section boring bar, which will have a negative impact on the actual boring. Therefore, selecting an appropriate taper ratio is important to improve the chatter stability. 


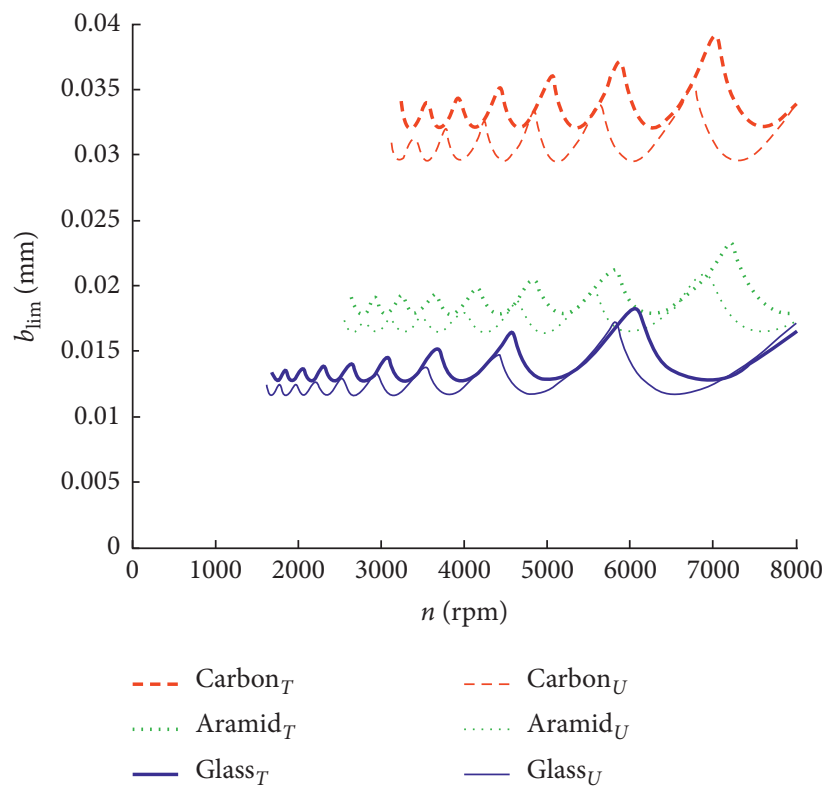

FIGURE 13: Effect of different composite materials on the chatter stability.

\section{Conclusions}

In this paper, the AMDM is introduced and used to compute the natural frequency of a tapered composite boring bar. To verify the effectiveness of the AMDM, we adopt the ANSYS software to compute the natural frequencies of the model under various tapered ratios. The results showed that the accuracy met the requirements and satisfied the chatter stability precision. Moreover, we verified the convergence of chatter stability of tapered composite boring bar. Based on these verifications, we analyze the natural frequency and chatter stability of the tapered composite boring bar in detail and draw the following conclusions:

(1) The natural frequency of a tapered composite boring bar is affected by the ply angle, $L / D$ ratio, $T / D$ ratio, and type of composite materials. By selecting a smaller ply angle, taper ratio, and $L / D$ ratio, one can get the larger natural frequency. Furthermore, by selecting a larger $T / D$ ratio and the carbon fiber composite material, one can get the larger natural frequency.

(2) The chatter stability of the tapered composite boring bar is related to the taper ratio, the ply angle, the stacking sequence, the $L / D$ ratio, the $T / D$ ratio, and the composite material type. The chatter stability increases with the decrease of the taper ratio, the ply angle, and the $L / D$ ratio. Moreover, by selecting a larger $T / D$ ratio, the carbon fiber material, and the proper stacking sequence, one can get one more stable tapered composite boring bar.

\section{Data Availability}

The data used to support the findings of this study are included within the article.

\section{Conflicts of Interest}

The authors declare that there are no conflicts of interest regarding the publication of this paper.

\section{Acknowledgments}

This work was supported by the National Science Foundation of China under Contract no. 11672166.

\section{References}

[1] K. Z. Y. Yen and W. C. Hsueh, "Suppression of chatter vibration in inner-diameter cutting," JSME International Journal. Ser. C, Dynamics, Control, Robotics, Design and Manufacturing, vol. 39, no. 1, pp. 25-33, 1996.

[2] J. R. Pratt, Vibration control for chatter suppression with application to boring bars, Ph.D. thesis, Virginia Polytechnic Institute and State University, Blacksburg, VA, USA, 1997.

[3] T. Smirnova, H. Akesson, and L. Hakansson, "Dynamic modeling of a boring bar using theoretical and experimental engineering methods Part 1: distributed-parameter system modeling and experimental modal analysis," The International Journal of Acoustics and Vibration, vol. 14, pp. 124-133, 2009.

[4] N. Lee, X. Liu, and J. Wang, "Structural design and vibration analysis of the built-in damping boring bar," DEStech Transactions on Computer Science and Engineering, vol. 1, pp. 129-137, 2018.

[5] J. P. Gurney and S. A. Tobias, "A graphical analysis of regenerative machine tool instability," Journal of Engineering for Industry, vol. 84, no. 1, pp. 103-111, 1962.

[6] J. Pratt and A. H. Nayfeh, "Boring bar chatter control," Proceedings of SPIE-The International Society for Optical Engineering, vol. 1, pp. 215-225, 1998.

[7] Y. Ren, W. Fen, and B. Ma, "Dynamic modeling of composite boring bars considering different boundary condition," IOP 
Conference Series: Materials Science and Engineering, vol. 382, pp. 1-12, 2018.

[8] J. R. Baker and K. E. Rouch, "Stability analysis of boring bars with asymmetry," Machining Science and Technology, vol. 6, no. 1, pp. 81-95, 2002.

[9] J. Qiu and R. Ge, "An improved stability lobe and turning chatter characteristic investigation," International Journal of Mechanical Sciences, vol. 149, pp. 338-348, 2018.

[10] M. H. Miguélez, L. Rubio, J. A. Loya, and J. Fernández-Sáez, "Improvement of chatter stability in boring operations with passive vibration absorbers," International Journal of $\mathrm{Me}$ chanical Sciences, vol. 52, no. 10, pp. 1376-1384, 2010.

[11] R. Rusinek, M. Wiercigroch, and P. Wahi, "Modelling of frictional chatter in metal cutting," International Journal of Mechanical Sciences, vol. 89, pp. 167-176, 2014.

[12] Y. Liu, Z. Liu, Q. Song, and B. Wang, "Development of constrained layer damping toolholder to improve chatter stability in end milling," International Journal of Mechanical Sciences, vol. 117, pp. 299-308, 2016.

[13] L. Li, B. Sun, and H. Hua, "Analysis of the vibration characteristics of a boring bar with a variable stiffness dynamic vibration absorber," Shock and Vibration, vol. 2019, Article ID 5284194, 13 pages, 2019.

[14] X. K. Luo, K. Cheng, X. C. Luo, and X. W. Liu, "A simulated investigation on the machining instability and dynamic surface generation," The International Journal of Advanced Manufacturing Technology, vol. 26, no. 7-8, pp. 718-725, 2005.

[15] Y. Altintas and M. Weck, "Chatter stability of metal cutting and grinding," CIRP Annals, vol. 53, no. 2, pp. 619-642, 2004.

[16] G. Litak, "Chaotic vibrations in a regenerative cutting process," Chaos, Solitons \& Fractals, vol. 13, no. 7, pp. 1531-1535, 2002.

[17] B. Tulasiramarao, D. K. Srinivas, and D. P. R. Reddy, “Analysis of stability in turning with secondary effects," IOSR Journal of Mechanical and Civil Engineering, vol. 14, no. 3, pp. 04-17, 2017.

[18] T. KalmárNagy and F. C. Moon, "Mode-coupled regenerative machine tool vibrations," Nonlinear Dynamics of Production Systems, Wiley-VCH, Weinheim, Germany, pp. 129-151, 2003.

[19] A. Gasparetto, "A system theory approach to mode coupling chatter in machining," Journal of Dynamic Systems, Measurement, and Control, vol. 120, no. 4, pp. 545-547, 1998.

[20] D. W. Wu and C. R. Liu, "An analytical model of cutting dynamics. Part 1: model building," Journal of Engineering for Industry, vol. 107, no. 2, pp. 107-111, 1985.

[21] D. W. Wu and C. R. Liu, "An analytical model of cutting dynamics. Part 2: verification," Journal of Engineering for Industry, vol. 107, no. 2, pp. 112-118, 1985.

[22] S. Nagano, T. Koizumi, T. Fujii, N. Tsujiuchi, H. Ueda, and K. Steel, "Development of a composite boring bar," Composite Structures, vol. 38, no. 1-4, pp. 531-539, 1997.

[23] D. G. Lee, H. Yun Hwang, and J. Kook Kim, "Design and manufacture of a carbon fiber epoxy rotating boring bar," Composite Structures, vol. 60, no. 1, pp. 115-124, 2003.

[24] C. Zhang, Y. Ren, S. Ji, and J. Zhang, "Analysis of the composite boring bar dynamic characteristics considering shear deformation and rotational inertia," Applied Science, vol. 10, no. 4, pp. 1-14, 2020.

[25] R. P. Goel, “Transverse vibrations of tapered beams," Journal of Sound and Vibration, vol. 47, no. 1, pp. 1-7, 1976.

[26] P. A. A. Laura and R. H. Gutierrez, "Vibrations of an elastically restrained cantilever beam of varying cross section with tip mass of finite length," Journal of Sound and Vibration, vol. 108 , no. 1, pp. 123-131, 1986.

[27] R. O. Grossi, A. Aranda, and R. B. Bhat, "Vibration of tapered beams with one end spring hinged and the other end with tip mass," Journal of Sound and Vibration, vol. 160, no. 1, pp. 175-178, 1993.

[28] S. H. Ho and C. o. K. Chen, "Analysis of general elastically end restrained non-uniform beams using differential transform," Applied Mathematical Modelling, vol. 22, no. 4-5, pp. 219234, 1998

[29] S. Abrate, "Vibration of non-uniform rods and beams," Journal of Sound and Vibration, vol. 185, no. 4, pp. 703-716, 1995.

[30] M. A. De Rosa and N. M. Auciello, "Free vibrations of tapered beams with flexible ends," Computers \& Structures, vol. 60, no. 2, pp. 197-202, 1996.

[31] Y. S. Ren, B. L. Ma, J. M. Ma, and W. L. Feng, "Effect of taper on dynamical characteristics of a composite boring bar," Machinery Design \& Manufacture, vol. 7, pp. 156-160, 2019.

[32] J.-C. Hsu, H.-Y. Lai, and C. K. Chen, "Free vibration of nonuniform Euler-Bernoulli beams with general elastically end constraints using Adomian modified decomposition method," Journal of Sound and Vibration, vol. 318, no. 4-5, pp. 965-981, 2008.

[33] J. Tian, "Analysis and prediction of regenerative chatter stability for passive constrained damping layer composite," MA.Eng. thesis, Shandong University of Science and Technology, Qingdao, China, 2018.

[34] K. Abbaoui and Y. Cherruault, "Convergence of Adomian's method applied to nonlinear equations," Mathematical and Computer Modelling, vol. 20, no. 9, pp. 69-73, 1994.

[35] P. Szuba, Q. Zou, G. C. Barber, and L. Yang, "Optimization of hollow cantilevered boring bar stiffness," Machining Science and Technology, vol. 9, no. 3, pp. 325-343, 2005. 